\title{
ICT in Language Learning - Benefits and Methodological Implications
}

\author{
Kristina Mullamaa \\ Language Centre, University of Tartu \\ Näituse 2, Tartu 51003, Estonia \\ E-mail: kristina.mullamaa@ut.ee
}

\begin{abstract}
ICT as a medium for teaching is becoming more and more acknowledged. In this article we wish to share some aspects of using ICT that have proved positive and stimulating both for students and the teacher. We share our experience in using the Blackboard e-learning environment for teaching language courses in English and Swedish (different levels), for learning terminology, and ESP (English for Specific Purposes). Our focus will be on how the web-based environment can be used for supporting student-centred learning, increasing student motivation, individualisation and cooperation in creating the study-materials, at the same time developing a feeling of "us" and of belonging together. Taking a look at our different past and current courses, we will view different ways of motivating students by engaging them in building the learning materials: data-bases on specific research topics, power-point presentations and on-line dictionaries. We analyse how the ICT solutions can be used as a support for different classroom activities, group-work and pair-work assignments; for independent work; for enforcing student-centred learning and the principles of individualisation; forming one's personal opinion, and being able to express it on topical issues.
\end{abstract}

Keywords: E-learning, ICT, Language learning, Individualisation, Motivation

\section{Introduction}

E-learning tends to create dissenting opinions. Some educationalists appreciate its values, others tend to be rather reserved to the option of having the electronic environment "overtake the classroom".

Our experience of using e-learning as a support to our eye-to-eye classes has proved to be positive and stimulating both for students and the teacher. At the same time, there has been a strong incentive from our university to encourage teachers to explore the possibilities of on-line learning.

Some years ago, the University of Tartu started to organise e-learning sessions called "coffee with e-learning". This was based on the example from Scandinavia. Suitably scheduled during the lunch break of the last working day in the week and offering tempting delicacies to coffee, the e-lunches introduced state-of-the-art knowledge about e-learning. The ICT solutions were taught by the IT-support staff who also became the tutors of the teaching staff during building and carrying out the e-courses.

Thus, by 2010 at the University of Tartu all distance learning courses and 30\% of the full-time courses should have a Web-based support (http://www.ut.ee/590864). Today, $34 \%$ of courses have some materials up at a parallel electronic system ÕIS. The project is supported by the EU-funded programmes "VANKeR" and "Best".

In language teaching, the educational and tutoring support available can be used in creating the e-learning environments for teaching general language courses in different languages at different levels; for learning terminology, and ESP (English for Specific Purposes) in different fields of specialisation. At the same time, ICT enables us to foster student-centred learning, individualisation and support building up a sense of belonging to a community. In the article below, we would like to share some of these experiences.

\section{The theoretical background}

\subsection{Student motivation and e-learning}

ICT supports the modern principles of learning and language acquisition. Individualisation, interaction and student motivation, often considered paramount in modern education theories, are necessarily a part of the process in ICT. As Theobald (2006: 1) points out, some students need extrinsic tools to increase their motivation. Intrinsic motivation, however, is "the ultimate goal of educators for their students" (ibid.). How to make students reach this? Intrinsic motivation is often attributed to finding a value in what students do. Theobald (2006: 1) concludes:

Helping students find value in learning through the implementation of various instructional strategies and multiple alternative and authentic forms of assessments, while maintaining high standards of student performance in an environment which encourages students to do their best work by effective, nurturing teachers, will help increase the motivational levels of all students.

Dörnyei and Otto (1998:65) give us a definition of L2 (second/ foreign language) motivation: 
In a general sense, motivation can be defined as the dynamically changing cumulative arousal in a person that initiates, directs, coordinates, amplifies, terminates, and evaluates the cognitive and motor processes whereby initial wishes and desires are selected, prioritised, operationalised and (successfully or unsuccessfully) acted out.

Hasanbegovic (2005) has reviewed a study on the impact of intrinsic motivation on e-learning in authentic computer tasks by Martens et al. 2004. The study allows her to conclude:

In line with the motivation theory of Ryan and Deci it is predicted and evidenced that intrinsically motivated students do more in a fixed time period as a result of their higher effort and persistence and will do different things in computer environments that allow for this liberty of choice (Hasanbegovic 2005).

A well-balanced ITC environment will enable students to feel the above and stay motivated throughout the learning process. Motivation, individualisation, learning in context and the activation of the learner - all buzzwords in modern education - are often a part and a parcel of a successful ICT support.

\subsection{Modern role sharing: learner responsibility and teachers' roles}

An equally important aspect is learner responsibility - the students' capacity to envision and pursue their goals. A modern student, especially at the university level, must know why and what s/he needs to study, and to be able to design and stick to their personal study plan. Wilson (1981: 61) points out that student development through the university years can be seen as follows:

One view is that student growth occurs through an invariant sequence of stages or levels in which progress from stage to stage implies a restructuring and reorganisation of what went before. 'Higher' stages are qualitatively different from 'lower' stages in terms of the way the individual thinks, feels or acts. Another influential view is that student development is to be seen in terms of mastery of a series of developmental 'tasks' which involve the individual's maturation in the different aspects of intellect, emotions and social relationships.

Today, the role of the teacher is that of an advisor, an expert in the field whose task is to support the student's development. This is much more creative and much more challenging than the more traditional "design and control the study process" concepts. Dörnyei (2001: 35) points out:

/.../ teachers are powerful motivational socialisers. Being the officially designated leaders within the classroom, they embody group conscience, symbolise the group's unity and identity, and serve as a model or a reference/ standard. They also function as an 'emotional amplifier' of the group whose appeals and examples are critical for mobilising the group /.../. Simply speaking, to lead means to direct and energise, that is, to motivate.

In education, as elsewhere, increased cooperation and neglecting the earlier rigid borderlines, is becoming more and more common practice. Day and Sachs (2004: 7) indicate:

The core democratic professionalism is an emphasis on collaborative, cooperative action between teachers and other educational stakeholders.

Kiggins and Cambourne (2007: 368-379) emphasise the importance of a "triadic partnership" (ibid. 374) from the very training of young teachers. Kiggins and Cambourne (ibid.) stress:

$/ \ldots /$ trust becomes a required element in the knowledge building process, and if friendship and trust are not present among the student cohort, this process is unlikely to occur.

At the same time, the responsibilities going along with the teaching profession per se increase. As Day and Sachs (2004: 7) point out:

It suggests that the teacher has a wider responsibility than the single classroom and includes contributing to the school, the system, other students, the wider community and collective responsibilities of teachers themselves as a group and the broader profession $/ . . . /$.

\subsection{Learning concepts in situated meanings: the possibilities for ICT}

J P Gee (2009: 15) points to the importance of learning of concepts in situated meanings. It is only if students have acquired and tried out the contents of concepts in situations that teach and test their real meaning, that learning has happened. Without that, students may be able to complete seemingly perfect "pen and paper" tests. However, at closer testing, they prove not to be able to solve real problems (cf. Gardner 1991, in Gee 2009: 15).

We suggest that ICT and web-based learning solutions offer the learners the possibilities for making the learning process more interesting and challenging. Some of the capacities here are attractive and enthusing, even similar to what has been pointed out as the educational reserve of video games. J P Gee suggests (2009) that the principles these follow often relate to the principles of encouraging active learning. Out of the capacities that Gee relates to positive learning techniques in video-games (Gee 2009: 22), we associate with ICT the following: interactivity, adaptability, a gradual build-up of the level of difficulty, and following the principle of the "cycle of expertise". 
Also, the modernity of the medium and its parallels to the developments in virtually all other spheres of human life, where the digital revolution reaches from citizen journalism to museum pedagogy (cf. Gottlieb 2009: 26-37), help to make it attractive.

A recent SRI International for the Department of Education in Estonia (http://www.ed.gov/rschstat/eval/tech/evidence-based-practices/finalreport.pdf) demonstrates that the learning results that have been reached by using ICT solutions are more profound than the learning results achieved through using traditional learning methods:

On average, students in online learning conditions performed better than those receiving face-to-face instruction. Over the 12-year span, the report found 99 studies in which there were quantitative comparisons of online and classroom performance for the same courses. The analysis for the Department of Education found that, on average, students doing some or all of the course online would rank in the 59th percentile in tested performance, compared with the average classroom student scoring in the 50th percentile.

Below, let us take a look at some practical implications of using ICT in our language teaching.

\section{The experience of using ICT in teaching general language courses and ESP}

\subsection{The general layout of the web-based courses and the main goals of using ICT support}

In our experience, ICT has proved to be a good environment for general language courses (English and Swedish at different levels), as well as for learning terminology and ESP (English for Specific Purposes) (Aviation English). The courses have been offered as a support for ordinary classroom teaching, i.e. the web-based courses usually:

run parallel to the face-to-face seminars

support what has been learned in the classroom

include exercises on texts/ grammar covered in the classroom

The main goals of using the ICT are to support:

learning and acquiring new vocabulary in English and Swedish

forming one's personal opinion and being able to express it on issues topical in one's field of specialisation, as well as topics of general interest (links to topical articles \& hot debates both in Estonia \& abroad, web-links, multimedia

resources)

learning ESP

This can be done in different ways, for example using the more traditional solutions like:

on-line vocabulary exercises on texts we read \& discuss in the classroom

links to self-correcting grammar exercises (individualisation)

on-line dictionary created by students step-by-step, course-by-course

information about different projects

e-mail

forum

self-tests on-line

a clear structure, course plan, calendar - important dates, dates for when to present one's work, field-trips always at the click of the mouse

personal feedback on different skills, on accomplishing different tasks

Out of the areas mentioned above, creating on-line dictionaries, power-point presentations and exercises integrated with the activities carried out in the classroom deserve further attention.

\subsubsection{Creating on-line dictionaries}

Our experience suggests that on-line dictionaries can prove most useful in learning ESP and creating terminology. This was especially conspicuous in the case of teaching Aviation English. In this discipline, we did not have established terminology in Estonian for many years, as aviation education in our language was eliminated in the 1940s and was restored only in 1993 with the creation of Tartu Aviation College. Terminology was developed in the lectures and workshops of the main field of study, sometimes also accompanied by finding the counterparts to items of English terminology in the English language lessons, with active cooperation with students. The on-line dictionaries served as a term-bank built by students in the field, accessible to the whole student community from the moment each respective student added their vocabulary item to the on-line environment. 


\subsubsection{Power-point presentations}

Something as basic as power-point presentations has proved to be most popular with students. Presented in the classroom, the power-point presentations remain up on the net, and offer students the possibility of revisiting the presentations they liked the most, checking up the new vocabulary items presented in the power-point reports, and revising new knowledge on topics interesting for them.

\subsubsection{Extension to activities in the classroom}

Exercises designed as an extension to activities carried out in the classroom support the acquisition of vocabulary, forming one's personal opinion, and being able to express it on topical issues. It enables students to understand their area of specialisation and many other important issues in a wider context and to put it into a perspective that stretches beyond their university, country, and continent.

Another important aspect is the possibility of immediately shaping the learning materials to answer the students' needs. It may, for example, be appropriate to add a grammar or vocabulary exercise in an area/ or on a topic that needs active learning or revision. Encouraging students to cooperate in the process of creating and shaping the study process keeps them interested and motivated.

\subsection{Web-based solutions integrated with classroom learning}

The web-based solutions also offer good possibilities for carrying out eye-to-eye lessons in the computer classroom. The ICT solutions can be used as a support for different classroom activities, e.g. the group-work and pair-work assignments in class, but also for follow-up independent work on classroom activities for students with a different learning style, or as preparatory work. The goal in all these instances is encouraging student-centred learning and the principles of individualisation (different interests/ levels/ needs). E-learning as a support for learning in the classroom enables us to make the study process more flexible and to better take into consideration the needs of different students. The students are active and " a part of the process".

\subsubsection{Multimedia possibilities}

For example, the Web-based environment can host different multimedia possibilities for developing speaking skills. It may be done in many different ways. One of the favourites of our students have been the jig-saw pair-work activities that involve:

watching different video-clips,

answering the different questions to both students that become in essence a short summary of the clip they have seen, and

finally, replaying the respective videos with one's partner with the voice on mute, the respective student in charge of a certain video providing a voice-over.

If you find an informative and interesting clip on a subject area you are currently working on with advanced students or an ESP group, such an activity can provide students with the latest information, buzz-words and key expressions on the subject area, at the same time offering them a fair amount of challenge.

\subsubsection{Finding and sharing background information through the Web}

Another popular activity is finding additional information on the texts, phenomena or people spoken about in our articles or student presentations. We often build this up as a group-work activity. And while in ordinary class-room settings the feedback information from the buzz groups remains preserved in our memory, or at paper boards, the ICT learning environment enables students to access their final feedback posted there also later during the course, wherever they are - at home or in Hawaii. Also, the current licences allow us to keep the courses open for participants for at least half a year after attending the course, thus offering perfect possibilities for a longitudinal learning process, and revisiting the materials beyond the official end of the learning cycle. This possibility, coupled with the attention of students from parallel groups and "future generations", is most stimulating, and even encourages them to have an unofficial friendly competition on whose report or power-point presentation looks the best.

\section{The benefits of using e-learning as a support for classroom teaching}

\subsection{E-learning as a support for classroom teaching}

ICT as a support for ordinary class-room teaching, and as a part of it, has the obvious benefits of:

easy access whenever and wherever you wish it

dematerialisation (less paper - more trees)

enabling us to use modern methodologies

individualisation (different interests/ levels/ needs) 
Contacts beyond our university, state, continent ("broadening the horizons"; "real English", or whatever foreign language for that matter)

Students have

an overview of topical issues, their context and background

easy access for quickly (!) finding inspiration for (continuing) the conversation

developing the skills for finding the right information, analyse, present and discuss it

developing the skills for using the e-environment and new technologies

developing responsibility for the learning process

forming one's own opinion

learning to (dare to) express it

\subsection{The ethical dimension: learning to have a say}

A Chinese proverb says: "teachers open the door, but you must enter by yourself." Our task is to encourage students. But it is not only the new vocabulary a good language course should give them. It is essential to consider the fact that the immediacy of the information and news reaching our students (through this new language) gives them an opportunity to be informed of and shape their opinion on important topics relating to our society and the "here and now".

As many renowned sociologist and researchers (cf. e.g. Cronin 2002, Pym 2005) have stressed, it is not enough to have an opinion - an educated person must express it to shape the society we live in. Indeed, much of the knowledge and ideas in the modern 2.0/3.0 Web world are related to who has the information and who has it first. And who else should be encouraged to learn to use it to the best of their capacity and following all the ethical principles than students of foreign languages, who in many ways are and become the window to/ from the world of their own society and culture.

\subsection{Building trust}

Anatole France has said: "nine tenths of education is encouragement". There can be no encouragement without trust (cf. Kiggins and Cambourne 2007: 374 in 2.2. above). As teaching in general, so can also e-learning be organised in different ways. For some, it may be:

a ready-made environment created by the teacher

teacher controlled, students present filled-in exercises, get marks

self-tests

"the teacher's button" with which to control the computers of students when we work together in the computer classroom.

In contrast to this, we have chosen to build our courses on the principles of trust. We believe that students:

can manage

are (almost) grown-ups

can take responsibility

are ( to a great extent) responsible

for their study process

Much depends on the teacher's authority type - whether the teacher is autonomy supporting or controlling. Dörnyei (2001a:37) points out:

Sharing responsibility with students, offering them options and choices, letting them have a say in establishing priorities, and involving them in the decision-making process enhance student self-determination and intrinsic motivation /../.

In our experience, supporting student autonomy shows that there is a trust for the teacher, and an increased responsibility for the learning process.

\subsection{Creating the feeling of belonging together}

In education, as elsewhere, increased cooperation and neglecting of the earlier rigid borderlines, is becoming more and more of a common practice. Such an approach also helps students to retain their motivation. Cocea and Weibelzahl (2006: 2-3) point to the connection between e-learning and the Social Cognitive Learning Theory SCT. In their view, personalization, adaptivity, affective tutoring and collaborative learning, as well as motivation - all aspects also we have emphasized above - all help to increase student satisfaction and learning quality: 
Personalization aims to make learning more effective and satisfying by adapting to the learner's needs and preferences. Among the benefits of adapting to the learner's motivation are: enhanced motivation and involvement, empowered learners - making them more responsible and active, increased satisfaction, better quality of learning etc.

Motivation is related to affective computing /.../, because self-concepts are always charged with emotions. Thus, affective agents could be used for both assessing motivation and intervention.

SCT also fits with collaborative learning, given the social framework taken in consideration by this theory and the way learning is influenced by the social context.

Rather contrary to what is sometimes supposed of a web-based environment, the experience shows that it often joins the students in the group. Offering them the possibility to communicate in an environment "natural" for them, the web-based course, if built up in a way that enables the students to participate and open up. It also serves to join

the different terms (over $\mathrm{X}$-mas, during the summer vacation)

different parallel groups (e.g. Group A and Group B learning the same subject)

different years of students learning the same subject

This can be supported through helping students create common databases. In our case, the different power-point presentations and on-line dictionaries created by students have been the most popular items, especially so when the data-base is built up over different study years and together with the parallel group(s). Needless to say, the profiles of friends from a parallel group, and their small roster presentations of themselves also deserve great interest by the fellow students. And while commonly created on-line dictionaries can prove motivating for learning (and creating!) terminology and ESP for advanced students, consider how useful even creating a small roster presentation, or reading those of others, can be for a beginner-level general language student in the first months of their learning practice/ studies.

Analysing our past and current courses we may see that the Web-based environment can help to develop the sense of belonging together. In addition to common learning activities mentioned above, this can also be done through documenting different joint activities. Different common study visits or museum visits, often especially when also documented, and shared, discussed and analysed through the Web, help to develop the sense of belonging together.

Creating a feeling of belonging enables students to open up, to share more information about themselves to group-mates. The supportive experience in "real life" encourages students to share more information digitally. And also vice versa the information presented in the virtual world makes a good foundation for developing good relations in the classroom. Such processes of merging the virtual with real life, relying for technologies to find a feeling of belonging, and rejoicing over the friends' real life presence happens all the time in many modern lives today. Allowing our students to pursue this way we allow them to communicate and develop in modes and context familiar to and inspiring for them.

It is important to remember that ICT can also help to create special "bridges" between the study periods, different study-years and student groups, helping to shape the feeling of "us".

\section{Conclusion}

Gunnar Handahl $(2004,2007)$ has pointed out the importance of the following dimensions in education:

* Level 1 = Action: You go and teach.

* Level $2=$ Theory and practice: The reasons why you go and teach. Your background, knowledge of pedagogy, methodological skills, experience as a teacher. Experience transferred to knowledge.

* Level 3 = Values: The ethical and political justification. Why am I doing what I do? Why am I teaching at all? What does it benefit to the people I teach as

individuals? To the society at large?

As demonstrated in the article above, the level of values and ethics may guide teachers through choosing their medium, procedures and communication patterns with communicating with their students. Behind many of the seemingly practical choices there is a worldview based on active research and being familiar with the recent theoretical approaches. Many years of teaching practice and - as a teacher in different learning groups - participant observation also help to analyse and shape the processes. Hopefully, anchorage in deeper theories, principles and ethics can support students in making meaningful choices.

With the development of Web 2.0 and 3.0 there are still endless opportunities for novelties, development and change. Students are becoming more and more engaged, the communication and learning are less and less teacher-centred. In these developments the role of teachers, students, and learning itself are continuously changing to offer exiting possibilities for further development. Many of these developments are to be discovered in the work process together with the students and colleagues from all over the world. 
Long before the e-learning era, Plato $\quad(428 \mathrm{BC}-348 \mathrm{BC})$ said:

"Someday, in the distant future, our grandchildren's grandchildren will develop a new equivalent of our classrooms. They will spend many hours in front of boxes with fires glowing within. May they have the wisdom to know the difference between light and knowledge”.

Hopefully, a student-centred approach based on individualisation, increasing the student motivation, and responsibility, can be of support on this way.

\section{References}

Cocea, M. \& Weibelzahl, S. (2006). Motivation - included or excluded from e-learning. http://www.easy-hub.org/stephan/cocea-celda06.pdf. Accessed October 2009.

Cronin, M. (2002). The Empire Talks Back: Orality, Heteronomy and the Cultural Turn in Interpreting Studies. In F. Pöchhacker, M. Shlesinger (Eds.), The Interpreting Studies Reader. London and New York: Routledge. 393-397.

Day, C. \& Sachs, J. (2004). Professionalism, performativity and empowerment: discourses in the politics, policies and purposes of continuing professional development. In: Day, C, Sachs, J. (Eds.), International Handbook on the Continuing Professional Development of Teachers. Open University Press. UK, Bell\& Brain Ltd, Glasgow. 3-33.

Dörnyei, Z. (2001a). Teaching and Researching Motivation. Pearson Education Limited. Malaysia, LSP.

Dörnyei, Z. (2001b). Motivational Strategies in the Language Classroom. Cambridge University Press. UK.

Dörnyei, Z \& Otto, I. (1998). Motivation in action: A process model of L2 motivation. Working Papers in Applied Linguistics (London: Thames Valley University), 4: 43-69.

Gardner, H. (1991). The unschooled mind. How children think and how schools should teach. New York: Basic Books.

Gee, J. P. (2008). Är videospel bra vid inlärning? / Are videogames good for knowledge acquisition?/ In: Kulturens Studia Generalia. Svenska kulturfonden. Oy Nord Print. 8-23.

Gottlieb, H. (2008). Digitala pedagogiska artefakter - nya verktyg för pedagoger och intendenter. /Digital artefacts new tools for teachers and museum personnell/. In: Kulturens Studia Generalia. Svenska kulturfonden. Oy Nord Print. 25-38.

Handahl, G. (2004/2007). Ethics of Teaching in Higher Education. Teacher trainer courses: Teaching in Higher Education given at Tartu University. Oslo University-Tartu University. University of Tartu, 2004-2007.

Hasanbegovic, J. (2005). Review of Martens, R. L et al (2004). The impact of intrinsic motivation on e-learning in authentic computer tasks. Journal of Computer Assisted Learning, Vol. 20, pp. 368-376. http://www.elearning-reviews.org/topics/pedagogy/readiness/2004-martens-et-al-impact-intrinsic-motivation-elearningauthentic-computer-tasks/. Accessed October 2009.

Kiggins, J. \& Cambourne, B. (2007). The knowledge building community program. In: T. Townsend, R. Bates (Eds.), Handbook of Teacher Education. Globalization, Standards and Professionalism in Times of Change. Springer, printed in the Netherlands. 365-381.

Pym, A. (2005). Action Research in Translation Studies. Paper presented at the conference New Research in Translation and Interpreting Studies, International Studies Group, Tarragona, Spain, 7.-8. Oct. 2005.

SRI International for the Department of Education in Estonia. http://www.ed.gov/rschstat/eval/tech/evidence-based-practices/finalreport.pdf. Accessed October 2009.

Theobald, M. (2006). Increasing Student Motivation. Strategies for Middle and High School Teachers. Corwin Press. A SAGE Publications Company, Thousand Oaks, California.

Townsend, T \& Bates, R. (2007). Handbook of Teacher Education. Globalization, Standards and Professionalism in Times of Change. Springer, printed in the Netherlands.

Townsend, T \& Bates, R. (2007). Teacher education in a new millennium: Pressures and possibilities. In: T. Townsend \& R. Bates (Eds.), Handbook of Teacher Education. Globalization, Standards and Professionalism in Times of Change. Springer, printed in the Netherlands. 3-25.

Wilson, J. D. (1981). Student Learning in Higher Education. Croom Helm London. New York - Toronto. 